\title{
Research and Practice in Teaching of Analytical Chemistry Based on Duifene PAD Class and Formative Evaluation
}

\author{
Xianjiu Liao, Yan Li, Qichuan Huang, Zhenzhong Li, Suoyi Huang, Xiufeng Huang, Qianli Tang* \\ Youjiang Medical University for Nationalities, Baise, China \\ Email: ^htmgx919@163.com
}

How to cite this paper: Liao, X. J., Li, Y., Huang, Q. C., Li, Z. Z., Huang, S. Y., Huang, X. F., \& Tang, Q. L. (2020). Research and Practice in Teaching of Analytical Chemistry Based on Duifene PAD Class and Formative Evaluation. Creative Education, 11, 1541-1551.

https://doi.org/10.4236/ce.2020.118112

Received: August 7, 2020

Accepted: August 25, 2020

Published: August 28, 2020

Copyright $\odot 2020$ by author(s) and Scientific Research Publishing Inc. This work is licensed under the Creative Commons Attribution International License (CC BY 4.0).

http://creativecommons.org/licenses/by/4.0/

(c) (i) Open Access

\begin{abstract}
Objective: This paper constructs a joint teaching mode based on the Duifene PAD class and formative evaluation, which is applied in the teaching of Analytical Chemistry, and explores its teaching effect. Methods: We selected undergraduate students of Pharmacy in our university as teaching objects that were randomly divided into the control group and the experimental group. The experimental group was taught in the joint teaching mode based on Duifene PAD class and formative evaluation, while the control group was taught in the traditional teaching mode. At the end of the teaching, we adopted questionnaires for investigation on their learning effect in the new teaching mode, and compared the learning experience among two groups of students and their final scores of Analytical Chemistry. Results: The students in the experimental group were satisfied with the learning effect in the new teaching mode; compared with the control group, their learning experience was more ideal; their final scores of Analytical Chemistry were also higher than those of the students in the control group. Conclusion: The teaching mode based on Duifene PAD class and formative evaluation can fully mobilize students' learning initiatives, bring about a fairer and more objective evaluation, and improve the students' independent learning ability effectively, which is worthy of continuous improvement and promotion in teaching.
\end{abstract}

\section{Keywords}

Duifene Platform, PAD Classes, Formative Evaluation, Analytical Chemistry, Information Technology, Medical Universities

\section{Introduction}

At present, big data, cloud computing and other new technologies are widely 
used. With the accelerated development of information technology, the overall informationization degree in the society is being promoted while the impact of information technology on education is becoming increasingly obvious. In the era of "Internet plus Education", we must vigorously promote the integration between information technology and course education, improve teachers' application of information technology, and renew the concept of teaching (Gou, 2020). Therefore, it is an inexorable trend in the cultivation of qualified medical professionals in the new era to promote the integration between information technology and course education, reform the existing classroom teaching mode, and provide students with varieties of educational environment and learning tools (Yao, Yang, Lin, Wu, \& Zheng, 2019).

The formative evaluation, intended to promote the development of students, evaluates the students' development in emotion, attitude, competence, strategy and other aspects while teaching and learning, and feeds the results back to teachers and students in time to facilitate the improvement of teaching methods for teachers and students (Wang, Gong, Zhu, Yang, Gao, He, Lin, \& Bu, 2020). The formative evaluation, different from the traditional summative evaluation, emphasizes the dynamic development of students as individuals, keeps focusing on students' learning process, and tries to understand the development needs among students, which can facilitate the development and cognition of students effectively. Therefore, it is of great significance to conduct a scientific and effective formative evaluation on students' learning (Wei, 2019). However, the lack of real-time data collecting methods and technical support set the formative evaluation in great difficulties when implementing. Education, under the context of "Internet plus", has gradually become a constituent of the Mobile Internet era. Duifene Teaching Platform, as a real-time interaction and communication platform, can perform the real-time tracking and record data, which provides a technical support as solution to the puzzle, thereby making the formative evaluation of mobile learning possible.

PAD class is a new mode for classroom teaching reform based on the cognitive psychology, which, in combination with the essence of both "lecture-style class" and "discussion-style class", as well as the characteristics in students' process to learn new knowledge, assigns the course time evenly to teachers' lectures and students' discussion. The PAD class can be divided into three steps, i.e. presentation, assimilation and discussion (Shi, Hu, \& Qin, 2018). Duifene Teaching Platform, matching with corresponding steps of PAD class in various features, can facilitate the simultaneous practice of PAD class and formative evaluation. Therefore, the teaching process can be accomplished in combination with the practice of classroom sign-in, in-class test, classroom questioning, classroom discussion and other whole-course formative evaluation systems via Duifene Teaching Platform. We have constructed a joint teaching mode based on the Duifene Platform PAD class and formative evaluation, which can collect the evaluation basis conveniently, thereby having eliminated the bottleneck in absence of evaluation evidence. The achievement enables the formative evalua- 
tion system to be applied in the whole teaching \& learning process effectively, helps achieve the goal of "keep a complete record of students' growth, and perfect the comprehensive quality evaluation", offers a timely feedback on all the teaching steps, promotes the development of students' comprehensive quality, and enhances their independent learning ability.

\section{Research Objects and Methods}

\subsection{Research Objects}

2017 and 2018 undergraduate classes of Pharmacy in Youjiang Medical University for Nationalities were selected as the research objects, of which, the 2017 undergraduate class was selected as the experimental group (54 students), and 2018 undergraduate class was selected as the control group (53 students). The course of Analytical Chemistry for the two groups was 72 credit hours, among which theory courses took 51 hours and practice courses took 21 hours. Analytical Chemistry of the 8th edition was selected by all of them as the textbook, which was edited by Chai Yifeng, People's Medical Publishing House. Basic conditions of students in the two groups, including sex, age and basics, etc., were comparable.

\subsection{Research Methods}

The experimental class used the Duifene Teaching Platform to assist teaching. In such practices as attendance, knowledge presentation, classroom questioning, online exercise, group discussion and teacher summary, teachers can complete the teaching tasks easily and flexibly with the platform. Irregular sign-in, test, discussion and other activities were carried out during the course; courseware, assignments, videos or related network resource links were uploaded after the course. The comprehensive performance of experimental class = formative evaluation scores $(40 \%)+$ final scores $(60 \%)$. The PAD class is aimed to spur students' learning initiatives in independent learning. Therefore, although the mode in combination with formative evaluation and summative evaluation is adopted, the formative evaluation of learning process is emphasized to a higher degree. The course assessment based on formative evaluation of Duifene Teaching Platform consists of 1) Presentation (15\%): including Duifene attendance, classroom questioning, online exercise, activities, teaching evaluation, voting, etc.; 2) Assimilation (15\%): including Duifene assignments, course resources, forum, questionnaire, etc.; 3) Discussion (10\%): including classroom discussion, achievement presentation, etc. The control class adopted the traditional teaching mode and summative evaluation system. The research introduced Duifene Teaching Platform into the formative evaluation in the analytical chemistry, which transformed the evaluation mode from the usual performance and summative tests to such modes as attendance, in-class tests, classroom questioning, online assignments, classroom discussion, offline assignments and summative tests. The evaluation system, with its emphasis on both result and process, re- 
flected the students' learning status and comprehensive ability in a relatively dynamic, objective and comprehensive way, which facilitated the development of students' comprehensive quality and gave full play to students' learning initiatives.

\subsection{Effectiveness Evaluation}

At the end of the curriculum, 66 students were selected at random for a questionnaire in which the students were required to evaluate the learning effect and experience regarding the joint teaching mode based on Duifene Platform PAD class and formative evaluation. Each item of the questionnaire is rated through Likert 5-grade scoring, in which 5 means very satisfied and 1 means very dissatisfied. Evaluation contents of the questionnaire include: 1) Investigating the students in the experimental group as the research objects on their learning effect in the teaching mode of Duifene Platform PAD class and formative evaluation; 2) Comparing the students' learning experience in the control group and experimental group; 3) Comparing the students' final scores of Analytical Chemistry.

\subsection{Statistical Results}

SPSS22.0 software was employed in the data analysis. The enumeration data is represented with $\mathrm{n}(\%)$, and the measurement data with $(\bar{x} \pm s)$. T-test was conducted as per the normal distribution. The difference was statistically significant with $P<0.05$.

\section{Results}

\subsection{Comparison of Learning Experience between the Control Group and Experimental Group}

In the era of "Internet plus Education", teachers can use the Internet teaching platform and traditional teaching modes to provide students with independent learning paths and rich learning resources by combining the classroom teaching and modern information technology, which will present the learning content to students in such digital way as video, thereby making the course learning more vivid and expressive and providing students with more sensory acupuncture to stimulate and improve students' learning experience. The results of the questionnaire among the students in the experimental class and control class, as shown in Table 1, indicate that the average satisfaction rate regarding the joint teaching mode based on the Duifene Platform PAD class and formative evaluation in the experimental class is $87.88 \%$, and the scoring range is mainly in the satisfaction range, accounting for $51.52 \%$; following "satisfied" is "very satisfied", accounting for $36.36 \%$; since there were few students who were "unsatisfied" or "very disappointed" (or the proportion was extremely low), the remaining scoring ranges basically fell into the general ranges. The average satisfaction rate regarding the traditional teaching mode among the students in the control class is $46.75 \%$, and the scoring range is mainly in the general range. The experimental 
Table 1. Comparison of the learning experience between the control group and the experimental group $(n=66, \%)$.

\begin{tabular}{cccccccc}
\hline & \multicolumn{2}{c}{ Experimental group $(\mathrm{n}=33, \%)$} & \multicolumn{2}{c}{ Control group $(\mathrm{n}=33, \%)$} \\
\cline { 2 - 7 } Survey items & $\begin{array}{c}\text { Very } \\
\text { satisfied }\end{array}$ & Satisfied & $\begin{array}{c}\text { Satisfaction } \\
\text { rate }\end{array}$ & $\begin{array}{c}\text { Very } \\
\text { satisfied }\end{array}$ & Satisfied & $\begin{array}{c}\text { Satisfaction } \\
\text { rate }\end{array}$ \\
\hline $\begin{array}{c}\text { Resource transfer } \\
\text { Classroom atmosphere }\end{array}$ & 36.36 & 51.52 & 87.88 & 9.09 & 33.33 & 42.42 \\
$\begin{array}{c}\text { Interaction between teachers and } \\
\text { students }\end{array}$ & 33.33 & 54.55 & 87.88 & 12.12 & 30.30 & 42.42 \\
$\begin{array}{c}\text { Interaction between students } \\
\begin{array}{c}\text { Timely communication } \\
\text { Timely evaluation }\end{array}\end{array}$ & 33.33 & 57.30 & 57.58 & 87.88 & 12.12 & 24.24 & 36.36 \\
Total average score & 45.45 & 39.39 & 84.85 & 15.15 & 48.48 & 63.64 \\
& 36.36 & 51.52 & 87.88 & 13.42 & 33.33 & 46.75 \\
\hline
\end{tabular}

group is significantly better than the control group concerning the satisfaction rate of 6 items such as resource transfer, and the differences are statistically significant $(P<0.01$, see Table 2). The joint teaching mode based on Duifene Platform $\mathrm{PAD}$ class and formative evaluation can effectively promote the interaction between teachers and students. Therefore, previously rigid and boring course of analytical chemistry is greatly improved, and the classroom atmosphere becomes more active.

\subsection{Evaluation on the Learning Effect of the Experimental Group and Control Group}

The result of questionnaire among the students in the experimental class and the control class, as shown in Table 3, indicates that the satisfaction rate regarding 7 items including knowledge \& ability mastering in the experimental group is significantly better than that in the control group, and the differences are statistically significant $(P<0.01)$. The overall satisfaction rate regarding the new teaching mode in the experimental class is high as $96.97 \%$, while that in the control group is $42.42 \%$. Of them, the scoring range in the experimental class on the new teaching mode mainly concentrates in the range of "satisfied", accounting for $60.61 \%$ on average; following "satisfied" is "very satisfied", accounting for $32.03 \%$; since there were few students who were "unsatisfied" or "very disappointed" (or the proportion was extremely low), the remaining scoring ranges basically fell into the general ranges. The average satisfaction rate regarding the traditional teaching mode among the students in the control class is $41.13 \%$, and the scoring range is mainly in the general range. Noticeably, the joint teaching mode based on Duifene PAD class and formative evaluation can effectively improve students' ability to master knowledge, to practice, to communicate, in self-learning and in information acquisition. In the objectivity of the evaluation, the new teaching mode can reflect the students' learning process in a more objective and authentic manner. 
Table 2. Learning experience scoring of the control group and experimental group $(\bar{x} \pm s)$.

\begin{tabular}{cccccccc}
\hline Group & $\begin{array}{c}\text { Number } \\
\text { of students }\end{array}$ & $\begin{array}{c}\text { Resource } \\
\text { transfer }\end{array}$ & $\begin{array}{c}\text { Classroom } \\
\text { atmosphere }\end{array}$ & $\begin{array}{c}\text { Interaction between } \\
\text { teachers and students between students }\end{array}$ & $\begin{array}{c}\text { Interaction } \\
\text { communication }\end{array}$ & $\begin{array}{c}\text { Timely } \\
\text { evaluation }\end{array}$ \\
\hline Observation group & 33 & $3.55 \pm 0.754$ & $3.52 \pm 0.712$ & $3.64 \pm 0.783$ & $3.39 \pm 0.556$ & $3.61 \pm 0.704$ & $3.48 \pm 0.795$ \\
Control group & 33 & $4.42 \pm 0.561$ & $4.30 \pm 0.637$ & $4.30 \pm 0.585$ & $4.21 \pm 0.545$ & $4.24 \pm 0.663$ & $4.18 \pm 0.635$ \\
$t$ & & 5.374 & 4.737 & 3.916 & 6.037 & 3.779 & 3.934 \\
$P$ & $<0.01$ & $<0.01$ & $<0.01$ & $<0.01$ & $<0.01$ & $<0.01$ \\
\hline
\end{tabular}

Table 3. Learning effect scoring of the observation class and control class $(n=66, \%)$.

\begin{tabular}{|c|c|c|c|c|c|c|c|c|}
\hline \multirow{2}{*}{ Survey items } & \multicolumn{3}{|c|}{ Experimental group $(n=33, \%)$} & \multicolumn{3}{|c|}{ Control group $(\mathrm{n}=33, \%)$} & \multicolumn{2}{|c|}{ Statistics } \\
\hline & Very satisfied & Satisfied & Satisfaction rate & Very satisfied & Satisfied & Satisfaction rate & $t$ & $P$ \\
\hline Ability to master knowledge & 27.27 & 72.73 & 100.00 & 9.09 & 30.30 & 39.39 & 5.615 & $<0.01$ \\
\hline Ability to practice & 42.42 & 54.55 & 96.97 & 6.06 & 30.30 & 36.36 & 6.728 & $<0.01$ \\
\hline Ability to communicate & 24.24 & 66.67 & 90.91 & 3.03 & 45.45 & 48.48 & 4.569 & $<0.01$ \\
\hline Self-learning ability & 42.42 & 45.45 & 87.88 & 12.12 & 27.27 & 39.39 & 4.524 & $<0.01$ \\
\hline Ability in information acquisition & 39.39 & 48.48 & 87.88 & 6.06 & 33.33 & 39.39 & 5.143 & $<0.01$ \\
\hline Evaluation objectivity & 24.24 & 63.64 & 87.88 & 3.03 & 39.39 & 42.42 & 4.560 & $<0.01$ \\
\hline Total average score & 32.03 & 60.61 & 92.64 & 6.49 & 34.63 & 41.13 & & \\
\hline
\end{tabular}

\subsection{Investigation on the Teaching Effect in Experimental Group}

The joint teaching mode based on Duifene PAD class and formative evaluation is a teaching mode combing online and offline methods, which can timely and effectively feeds back the learning process of students. Duifene Teaching Platform records the learning status of students in the teaching process in detail, so that teachers can evaluate the students' learning process and promote their self-sustainable development easily. Upon the completion of the new teaching mode, a questionnaire on the teaching effect of the new teaching mode among the students in the experimental group, whose result, as shown in Table 4, indicates that the average satisfaction rate in the experimental class is as high as $93.51 \%$, and the scoring range concentrates in the range of "satisfied" (61.04\% in average); following "satisfied" is "very satisfied", accounting for $32.47 \%$. The result suggests that the new teaching mode was highly praised by students and conducive to their development of independent learning.

\subsection{Performance Comparison in the Control Group and Experimental Group}

To explore the effect of formative evaluation modes on students' academic performance, we compared the summative test and comprehensive performance in their effects on the academic performance. In the results of analytical chemistry, the final result of the experimental group was $(77.85 \pm 9.737)$, the comprehensive result was $(85.32 \pm 5.901)$, the lowest score was 72.16 , and the highest score 
Table 4. Investigation on the teaching effect in the experimental class $(n=66, \%)$.

\begin{tabular}{|c|c|c|c|}
\hline Survey items & $\begin{array}{l}\text { Completely } \\
\text { agree }\end{array}$ & Agree & Consent rate \\
\hline Do you think it is necessary to employ a new teaching mode? & 33.33 & 63.64 & 96.97 \\
\hline Do you look forward to a new teaching mode? & 24.24 & 69.70 & 93.94 \\
\hline The new learning mode helps expand the classroom teaching & 39.39 & 57.58 & 96.97 \\
\hline $\begin{array}{l}\text { The new learning mode can build a relatively fair evaluation } \\
\text { system }\end{array}$ & 30.30 & 60.61 & 90.91 \\
\hline $\begin{array}{l}\text { The new learning mode can build a harmonious classroom } \\
\text { atmosphere }\end{array}$ & 39.39 & 51.52 & 90.91 \\
\hline The learning mode can help change the learning habits & 24.24 & 63.64 & 87.88 \\
\hline The new learning mode can enrich the teaching activities & 36.36 & 60.61 & 96.97 \\
\hline Total average score & 32.47 & 61.04 & 93.51 \\
\hline
\end{tabular}

was 96.06 , at a pass rate of $100 \%$; the final result of the control group was (56.98 $\pm 9.848)$, and the comprehensive performance was $(72.22 \pm 6.094)$. The result suggests that the final results and comprehensive performance of the experimental group were better than those of the control class, manifesting a better teaching effect. The students also thought that the formative evaluation system based on Duifene Teaching Platform was more objective and conductive for their mastery of professional knowledge, fulfillment of learning initiatives and improvement of comprehensive quality.

\section{Discussion}

PAD class was introduced as a new teaching mode because the traditional teaching and evaluation modes had been inapplicable, and the evaluation reform was imperative (Han, Lin, \& Wang, 2019). The formative evaluation, inherently required in the teaching mode of Duifene PAD class, shall be combined with attendance, in-class tests, classroom questioning, online assignments, classroom discussion, offline assignments and other steps on Duifene Teaching Platform to implement the formative evaluation in the whole teaching process, construct a multi-stage, multi-level, multi-perspective, scientific, reasonable and objective, comprehensive and humanized evaluation mode, stimulate students' learning initiatives, improve their self-learning ability and further improve the quality of course education and teaching.

1) Design a variety of interactive activities to enrich teaching activities

According to the modern educational theory, the teaching is more of a process where students develop their own abilities than of one where they cognize under teachers' instruction. Therefore, the teachers shall design a variety of interactive activities while teaching, create learning context, enhance students' awareness of participation, and instruct students to think initiatively to improve the teaching effect (Li, Zheng, Feng, Liu, \& Ma, 2019). The joint teaching mode, based on Duifene PAD class and formative evaluation, facilitated the integration of in- 
formation technology and course education, eliminated the limitations of traditional classroom teaching, and provided teachers and students with such function modules as random allocation, forum, WeChat message, classroom questioning, questionnaire, voting, activities, teaching evaluation, barrage discussion and students' mutual testing, which helped conduct a variety of interactive activities where teachers can view the interaction process of students and provide a basis for comprehensive and in-depth understanding and evaluation of their students. In addition, the assimilation, based on Duifene Teaching Platform, effectively expanded the depth and extent of self-taught contents, and guaranteed the effect of students in the discussion. The joint teaching mode, based on Duifene PAD class and formative evaluation, mobilized students' initiatives in learning, provided various teaching activities, stimulated students' aspiration, and further spurred their learning. According to the result of questionnaire, $87.88 \%$ of students in experimental group were satisfied with the interaction between teachers and students in the new teaching mode; $90.91 \%$ of them were satisfied with the interaction between the students; $87.88 \%$ were satisfied with the resource transfer; $96.97 \%$ believed it was necessary to implement the new teaching mode; $93.94 \%$ looked forward the future application of new teaching mode in other subjects; $96.97 \%$ believed the new learning mode by integrating information technology and course education would help expand the classroom teaching; $96.97 \%$ thought the teaching activities in new learning mode rich and colorful.

2) Improve the efficiency of formative evaluation based on the quantitative evaluation in Duifene Teaching Platform

Compared with the traditional course evaluation, this paper introduces Duifene Teaching Platform into the formative evaluation system where attendance, in-class test, classroom discussion, group cooperation and online assignment are employed as assessment measures, to record the traces of students' progress in an all-round way. The new teaching mode adopts formative evaluation to distribute the learning evaluations to a whole semester. Through the multi-perspective process evaluation on learning and learning effect, the evaluation result will be more authentic and accurate, which can facilitate students' self-learning ability, thereby enabling students to improve themselves continuously while learning (Wang \& Zong, 2020). With such mode based on Duifene Teaching Platform and formative evaluation, teachers can optimize their teaching designs based on students' learning status acquired in time to improve the teaching effect. According to the result of questionnaire, $84.85 \%$ of the students in experimental group thought that the evaluation of the new teaching mode was timelier; $87.88 \%$ thought that the evaluation process of the new teaching mode was more objective; $90.91 \%$ thought that the new learning mode can construct a relatively fair evaluation system.

3) The mode enlivened the classroom atmosphere and consolidated students' dominant position in learning

While teaching based on Duifene PAD class and formative evaluation, the 
students were required to take the initiatives in participating in classroom questioning, online assignments, group discussion and offline homework, which facilitated students' transformation from "passive learning" to "active learning", thereby improving their dominant positions in learning. Therefore, learning for them became an active process of taking in knowledge and sharing views. The traditional teaching modes are dominated by teacher's presentation in absence of heated discussion, which is not conducive to the construction of a harmonious classroom atmosphere. However, the new teaching mode succeeded in enlivening the previously silent classroom atmosphere. The "silent majority" in the past has been gradually transformed into the "main force in discussion"; the new teaching mode also stimulated students' interest in learning by replacing the dominant position of teachers in the traditional classroom with that for students, maximized the students' initiatives in learning, and raised the efficiency of teaching fundamentally. According to the result of questionnaire, $90.91 \%$ of the students in experimental group thought that the new learning method could construct a harmonious classroom atmosphere; $87.88 \%$ thought that the new learning mode was conductive to the transformation of learning habits; $87.88 \%$ thought that the new teaching mode could enhance the self-learning ability.

4) The mode helps improve students' comprehensive ability

The new teaching mode, via the change of knowledge presentation, assimilation and discussion, changes the "teacher-centered" teaching concept, constructs a "student-centered" teaching concept, establishes an idea of cooperative teaching between teachers and students, gives more emphasis to the development of students' comprehensive ability, and facilitates students' sustainable development. To complete various learning tasks such as classroom discussion, group study and online assignments, the students must consult varieties of literatures and learning materials after class, which broadened their horizons, enlivened their thinking, and enabled them to learn about the development frontier of interdisciplines for analytical chemistry. To some extent, the new teaching mode cultivated the students' ability to acquire information and master knowledge. In addition, since the repeated division and cooperation for group learning, to some extent, cultivated the students' ability to communicate and practice, have been cultivated, their comprehensive quality was significantly improved. According to the result of questionnaire, $100 \%$ of the students in the experimental group thought that their ability to master knowledge had been improved; $87.88 \%$ thought their ability to obtain information had been improved; $90.91 \%$ thought their ability to communicate had been improved; $96.97 \%$ thought their ability to practice had been improved.

\section{Conclusion}

To sum up, the joint teaching mode based on Duifene PAD class and formative evaluation has changed the "teacher-centered" teaching concept and constructed a "student-centered" teaching concept. It has broken the traditional mode featured with "teacher-centered teaching, one-way communication, passive learn- 
ing, and result-oriented evaluation", and constructed a new teaching mode characterized by "information-technology-supported teaching, student-dominated learning, two-way interaction, active learning, and learning-process-oriented evaluation". The new mode puts more emphasis on the deep integration of information technology and course teaching, and on the students' dominant position in learning. By dint of collecting students' learning information via Duifene Teaching Platform, as well as such activities as attendance, in-class tests, classroom questioning, online assignments, classroom discussion, offline assignments and summative test, the mode has produced an objective, scientific and feasible formative evaluation system of analytical chemistry, which can evaluate students from multiple perspectives, record and track their progress any time, thereby promoting their initiatives in acquiring knowledge, enhancing their self-confidence and sense of achievement at all teaching stages, and helping improve their comprehensive ability. In addition, the teachers can also benefit a lot. In the new teaching mode, teachers must update their teaching concepts, redefine their roles, improve their information literacy, and enhance their information-based teaching ability. By such means, their quality will also be improved, which promotes a win-win situation in teaching, making the mode worthy of continuous optimization and promotion in teaching.

\section{Fund Program}

Guangxi higher education undergraduate teaching reform project in $2018+$

"Research and Practice of PAD Classes based on Duifene Platform Combined with Formative Evaluation in Undergraduate Teaching-Taking Analysis and Testing Related Courses of Medical Universities in Ethnic Regions as Examples" + (2018JGA237).

\section{Conflicts of Interest}

The authors declare no conflicts of interest regarding the publication of this paper.

\section{References}

Gou, J. (2020). Empirical Research on Online Teaching and Normalization of University Teachers-Illustrated by Tianjin University of Science and Technology. China Education of Light Industry, No. 3, 5-13.

Han, S., Lin, J., \& Wang, Q. (2019). Practice and Thinking on Teaching Reform of Introduction to Basic Medicine Based on PAD Class. Journal of Guangxi University of Traditional Chinese Medicine, 22, 78-81.

Li, J., Zheng, Y., Feng, W., Liu, H., \& Ma, D. (2019). Formative Evaluation on the Course of Strengthened Instrumental Analysis Based on Moso Tech Class. Health Vocational Education, 37, 41-42.

Shi, Y., Hu, J., \& Qin, H. (2018). Practical Exploration of Teaching Reform of Seasonal Febrile Diseases Based on PAD Class. Lishizhen Medicine and Materia Medica Research, 29, 440-443. 
Wang, P., Gong, L., Zhu, X., Yang, J., Gao, J., He, J., Lin, A., \& Bu, W. (2020). Practical Exploration of Formative Evaluation Based on Rain Classroom Teaching Mode in Genetics Teaching. Journal of Youjiang Medical University for Nationalities, 42, 385-388+391.

Wang, S., \& Zong, X. (2020). Theoretical Connotation and Practical Reflection of Formative Evaluation. Journal of Teaching and Management, No. 15, 1-4.

Wei, J. (2019). A Preliminary Study on Formative Evaluation of College English Teaching Based on E-Learning Platform. Higher Education Forum, No. 2, 28-32.

Yao, Q., Yang, L., Lin, M., Wu, X., \& Zheng, Y. (2019). Exploration and Practice of Integrating Modern Information Technology into Medical Education and Teaching. Anatomy Research, 41, 342-343. 